\title{
A newborn with developmental delay diagnosed with $4 q 35$ deletion and 10p duplication
}

\author{
Beom Joon Kim ${ }^{1 \oplus}$, Woori Jang ${ }^{2 \oplus}$, Myungshin Kim $^{3 \oplus}$, and YoungAh Youn ${ }^{1, *(1)}$ \\ ${ }^{1}$ Department of Pediatrics, Seoul St. Mary's Hospital, College of Medicine, The Catholic University of Korea, Seoul, Korea \\ ${ }^{2}$ Department of Laboratory Medicine, College of Medicine, Inha University Hospital, Incheon, Korea \\ ${ }^{3}$ Department of Laboratory Medicine, Seoul St. Mary's Hospital, College of Medicine, The Catholic University of Korea, Seoul, Korea
}

\begin{abstract}
We report the case of an infant with a $4 q 35.1$ deletion with 10p duplication. This mutation is rarely reported in the literature and has been found to have variable clinical findings, often including developmental delay. In this case, the condition was detected by chromosomal microarray analysis after initial manifestation of a feeding problem and developmental delay. Minor dysmorphic features with abnormal neurological examination led to further evaluation. The father's chromosome complement was 46, XY, t(4;10)(q35;p12.2). Parental balanced translocation can go unrecognized, because affected individuals are often phenotypically healthy until they have fertility issues such as recurrent miscarriages or children with severe congenital disorders. Genetic diagnoses help to establish a clear family genetic background that permits the development of clear treatment strategies. Prenatal counseling can also help to understand the possible risks associated with pregnancy or future child planning.
\end{abstract}

Key words: Chromosome 4, Developmental disabilities, Deletion 4q35, Gene duplication, Chromosome deletion.

\section{Introduction}

Deletion of the long arm of chromosome 4 from band $4 q 34$ is a rare mutation, with an approximate incidence of 1 in 100,000 $[1,2]$. The $4 q 35$ deletion of chromosome 4 along with duplication of the terminal short arm of chromosome 10 is an unbalanced product of a parental reciprocal translocation, and has an incidence of 10-20\% [2,3]. Individuals with classical phenotypes inherited their $4 q$ deletion from a normal or mildly affected parent [3]. The syndrome caused by this deletion is characterized by intellectual disability, learning difficulty, autism or autism spectrum disorders, and developmental delay [2]. The presence of coarse facial features is characteristic of the disorder, with hypotelorism, anteverted nares, rotated or low-set ears, and clinodactly [4-6]. Cardiac defects such as atrial septal defect (ASD), ventricular septal defect, and pulmonary stenosis, and genitourinary anomalies such as hydronephrosis, inguinal hernia, and hypogenitalism are also reportedly associated with this syndrome $[6,7]$. Congenital hearing impairment has also been reported, with the appearance of immunological disturbances at a later point in life [6]. Small terminal deletions of $4 q$ do not seem to produce gross abnormalities, especially during the neonatal period, a fact which may delay diagnosis; the syndrome's main clinical features are mild to moderate intellectual disability and vague facial dysmorphism. The features are considered nonspecific and often seen in chromosomal imbalances, so a

Received: 14 October 2020, Revised: 18 November 2020, Accepted: 20 November 2020, Published: 31 December 2020

*Corresponding author: YoungAh Youn, M.D., Ph.D. (iD https://orcid.org/0000-0001-9083-2414

Department of Pediatrics, The Catholic University of Korea, Seoul St. Mary's Hospital, 222 Banpo-daero, Seocho-gu, Seoul 06591, Korea.

Tel: +82-2-2258-6191, Fax: +82-2-537-4544, E-mail: lea732@hanmail.net

Conflict of interest: The authors declare that they do not have any conflicts of interest.

(c) This is an open-access article distributed under the terms of the Creative Commons Attribution Non-Commercial License (http://creativecommons.org/licenses/by-nc/4.0/) which permits unrestricted non-commercial use, distribution, and reproduction in any medium, provided the original work is properly cited.

(c) Copyright 2020 by the Korean Society of Medical Genetics and Genomics 
distinctive, recognizable syndrome cannot be identified. In this study, we report the case of a newborn who was eventually diagnosed with $4 q 35$ deletion with duplication of the terminal short arm of chromosome 10 (p15.3p11.23). We speculate that the 10p duplication, together with the $4 q 35.1$ deletion, may have produced this child's characteristic phenotype, and may be relevant to the developmental delay observed in this patient. Balanced translocation carriers may be healthy with no signs of developmental problems and are often unaware of the possibility of miscarriage or birth of a child with chromosomal disorders. Genetic consultation can facilitate the identification of balanced translocation carriers.

\section{Case}

The study was approved by the Ethics Committee of Seoul St. Mary's Hospital, The Catholic University of Seoul, Korea (\#KC16ZISE0528). Full informed parental consent was obtained prior to initiating our investigation.

An eight-day-old infant visited our hospital due to jaundice. She was born via cesarean section at 38 weeks and 3 days, with a low birth weight $(2.24 \mathrm{~kg})$. She was the first baby in the family. The mother reported no history of abortion. She had intrauterine growth restriction, and her height and weight were within the 10th percentile. Her weight loss within eight days of life was $10 \%$, and she displayed decreased skin turgor and lack of activity. The jaundice was assumed to be due to weight loss and dehydration. After phototherapy with appropriate intravenous hy-

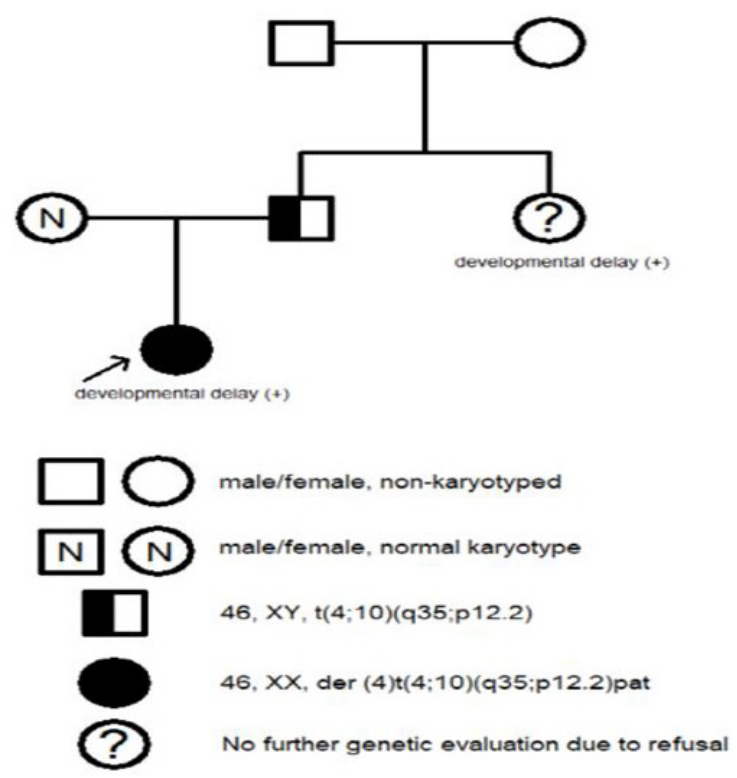

Fig. 1. Pedigree; balanced translocation in the father's family. dration, the jaundice improved. However, because her suckling was weak, with short endurance and inadequate coordination of swallowing, she never reached full feeding potential $(100 \mathrm{~mL} /$ $\mathrm{kg} /$ day). On neurological examination, she was floppy, with severe head lag and a positive inverted-U sign. Her facial features were vaguely dysmorphic, with frontal bossing, hypotelorism, anteverted nares, and low-set ears. Micrognathia was also observed. Large ASDs measuring $7 \mathrm{~mm}$ were found. The kidney and bladder sonograms were normal, as were the results of thyroid function tests. To assess any genitourinary abnormality, a kidney and bladder sonogram was performed; the results were normal.

After five days of oromotor stimulation therapy (stimulation of muscles involving sucking and swallowing coordination), her suckling was still weak. Full bottle feeding was not achieved, and her weight loss continued. Given the abnormal neurological examination, we performed a brain magnetic resonance imaging (MRI) for the detection of any structural abnormalities. The brain MRI results were interpreted as mega cisterna magna. This can be a normal anatomical variation with no clinical significance, as there is no associated cerebellar anomaly. As the auditory evoked and visual evoked potentials did not respond to any stimulation, retesting was scheduled for three months later.

After seven days of oromotor stimulation tests and continuous feeding practice, the infant's sucking power improved, and full oral feeds were established by 21 days of age. She was discharged 13 days after hospitalization, with full oral bottle feeding. At the outpatient clinic, she gained an appropriate amount of weight-a total of $400 \mathrm{~g}$ over two weeks-but still had hypotonia with dysmorphic facial features. Investigation

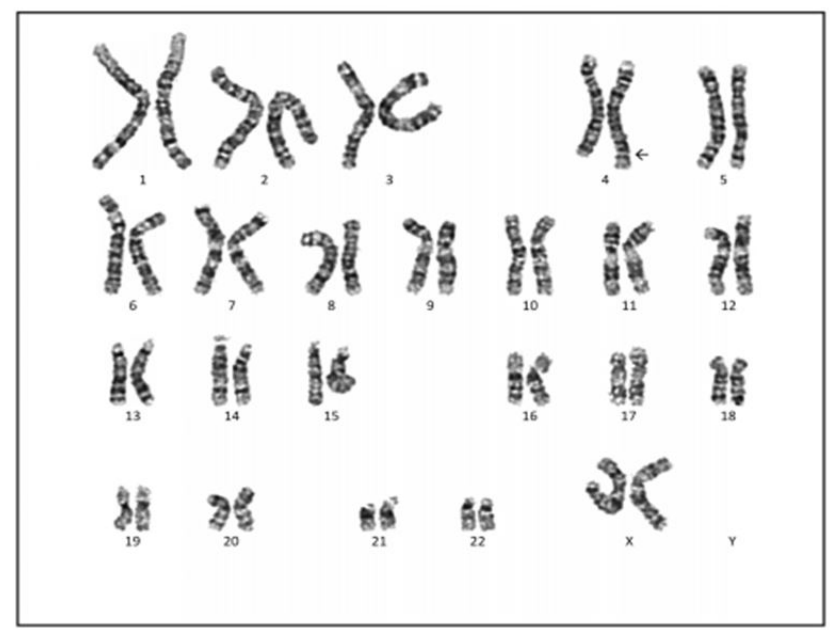

Fig. 2. Chromosome study; 46, XX, der(4)t(4;10)(q35;p12.2)pat. The 4 q35.1 deletion with 10 duplication was found in the chromosomal study. 
of the father's family history revealed that the patient's aunt (the father's younger sister) had been diagnosed with low 10 and learning disability (Fig. 1). More detailed genetic evaluation of the patient's aunt was not available due to the family's refusal of further evaluation. Genetic analysis of the patient identified terminal deletion of the long arm of chromosome 4 from band $4 q 34 ; 46, X X$, der (4)t(4;10)(q35;p12.2)pat (Fig. 2). A $4 q 35.1$ deletion with 10 duplications was identified by chromosomal analysis. The mother's chromosomal complement was normal female, and her father's chromosomal complement was $46, X Y, t(4 ; 10)(q 35 ; p 12.2)$. The microarray report manifested arr[GRCh37]4q35.1q35.2(185274461_190469337)x1,10p15 .3p11.23(148206_29975521)x3 pat (Fig. 3). Our patient was followed up regularly at our pediatric outpatient day clinic. Her neurological development was also monitored at the pediatric rehabilitation center. At the four-month visit, she clearly showed delayed development with significant head lag, inability to turn over, and general hypotonia. The four-month Korean developmental screening test showed delayed motor, cognitive, language, and socio-emotional development. Throughout her life, she is expected to be followed up regularly, to monitor her growth, heart, the possibility of immunologically mediated infections, and global developmental delay.

\section{Materials and methods; Chromosomal microarray}

Initial cytogenetic analyses of the child indicated an abnormal karyotype of 46, XX, der (4)t(4;10)(q35; p12.2) (Fig. 2). Array comparative genomic hybridization analysis was performed (Agilent Technologies, Santa Clara, CA, USA) (Fig. 3). Genomic DNA was extracted from peripheral blood using the OIAamp DNA Mini Kit (Qiagen, Hamburg, Germany). The DNA was quantified spectrophotometrically using an ND-1000 spectrophotometer (Nanodrop Technologies, Wilmington, DE, USA).

\section{Discussion}

Deletion of the long arm of chromosome 4 has been reported to be associated with variable clinical findings, including developmental delay and intellectual disability. We report an infant with a 4 q35.1 deletion (5.2 Mb in size) with 10 duplications,
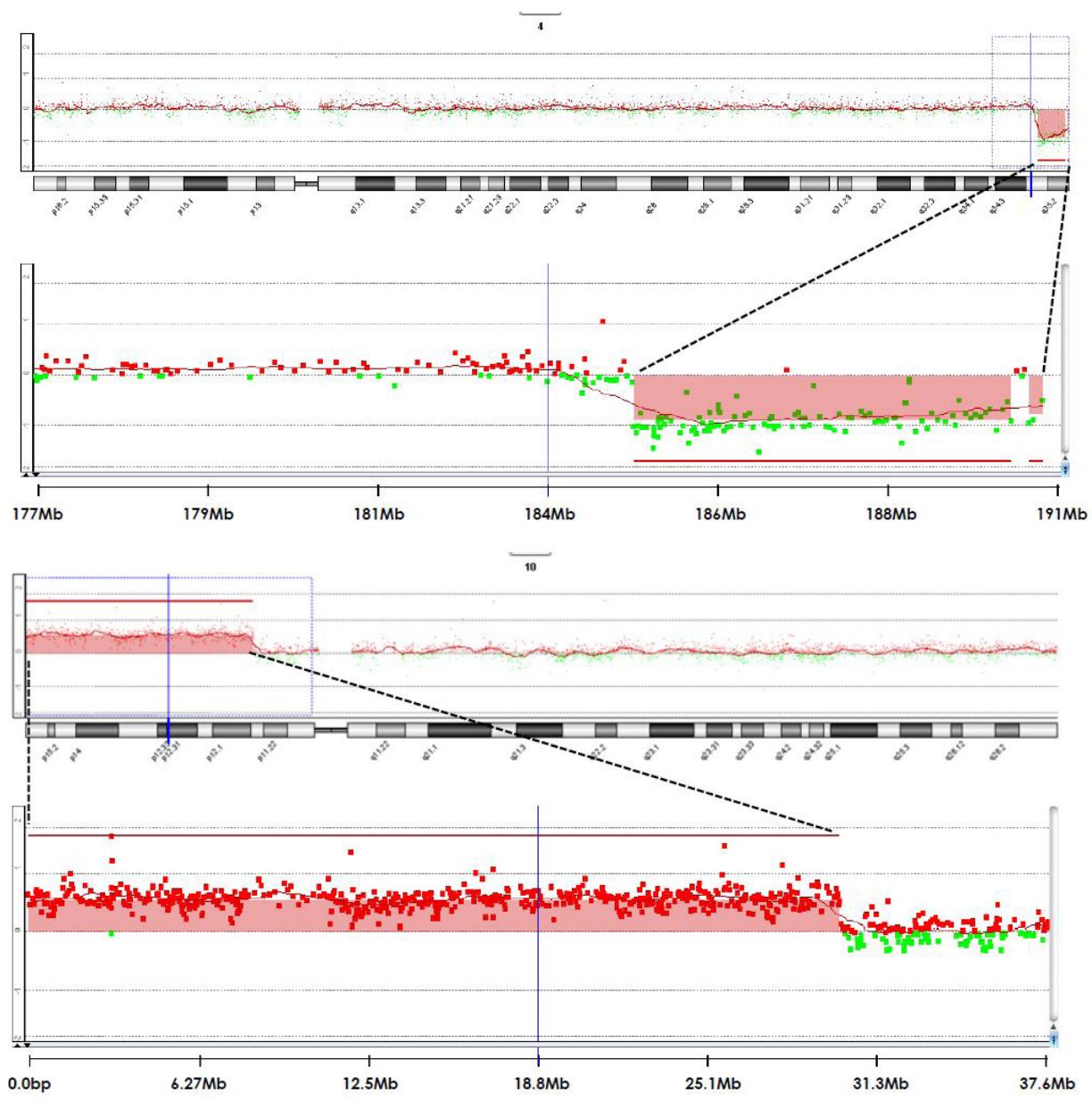

Fig. 3. Microarray report;arr[GRCh37] 4q35.1q35.2(185274461_190469337)x1,10p 15.3p11.23(148206_29975521)x3 pat. Array comparative genomic hybridization analysis showed a chromosomal heterozygous deletion of approximately $5.2 \mathrm{Mb}$ spanning from 4q35.1 to 4q35.2 (185274461_190469337) and a $29.8 \mathrm{Mb}$ heterozygous duplication at the 10p15.3p11.23 region (148206_29975521). 
detected by chromosomal microarray analysis. At eight days old, our patient had no significant birth history, but exhibited jaundice resulting from poor feeding, a symptom which would normally not warrant examination for genetic disorders. Genetic studies were performed when the feeding problem continued, and neurological abnormalities were apparent.

A case similar to ours was that of an eight-year-old girl with $4 q 35$ leading to deletion of the terminal long arm of chromosome 4 [6]; the proband in that case also had a mask-like facial appearance, with hypotelorism, anteverted nares, and low-set ears. As in our case, the patient had ASD, but it closed spontaneously. A nephrectomy was performed due to congenital hydronephrosis, which was diagnosed at six years of age. Her vision, hearing, and MRI findings were all normal. However, she had a variety of inflammatory symptoms, including frequent infections of the upper and lower airways, chronic polyarthritis, especially in the knees, and frequent stomach pains, suggestive of inflammatory bowel disease. A 10p15 duplication may affect the IL15RA, IL2RA, and PRKCO genes, which are involved in immune responses resulting from immune dysfunction. IL2RA and IL15RA are receptors for interleukin 2 (IL-2) and IL-15, respectively, and they are both found to be upregulated in chronic inflammation, in conditions such as rheumatoid arthritis and Crohn's disease [7].

Our patient will have to be carefully monitored for impaired immune function later in life, which may manifest as infection or chronic inflammatory diseases. Congenital heart defects are reported in about $60 \%$ of patients with $4 q$ deletion syndrome [8]. There has been a report of an eight-month-old male patient with congenital heart defects, growth delay, and minor skeletal anomalies, with a loss of $11.6 \mathrm{Mb}$ of genomic material from the long arm of chromosome 4, at 4q32.3-q34.3. A number of reports implicate chromosome 4q35.2 in ASD or congenital heart diseases [8]. Many individuals with chromosome $4 q$ deletions have similar clinical characteristics with associated anomalies (Table 1) $[4,9,10]$. These cases also manifested dysmorphic features with abnormal neurological examination, which led to genetic study for final diagnosis. Our child needs to be followed up regularly at our pediatrics department to assess her general growth, any signs of immunological diseases, and neurologi-

Table 1. Clinical characteristics in cases with chromosome $4 \mathrm{q}$ deletions

\begin{tabular}{|c|c|c|c|c|c|}
\hline Study & Our case patient & $\begin{array}{c}\text { Taub et al. } 2012 \text { [9] } \\
\text { Case } 1\end{array}$ & $\begin{array}{c}\text { Strehle et al. } 2012 \text { [4] } \\
\text { Case } 2\end{array}$ & $\begin{array}{c}\text { Strehle et al. } 2012 \text { [4] } \\
\text { Case } 3\end{array}$ & $\begin{array}{c}\text { Duga et al. } 2014 \text { [10] } \\
\text { Case } 4\end{array}$ \\
\hline Karyotype & $\begin{array}{l}\text { 46, XX, der (4)t(4;10) } \\
\text { (q35;p12.2)pat }\end{array}$ & $\begin{array}{l}\text { 46, XX, del (4) } \\
\text { (q33). ishdel (4) } \\
\text { (q33)(4qter-) }\end{array}$ & $\begin{array}{l}\text { 46, XY, del (4) } \\
\text { (q31.1?).ish der (4) } \\
\text { (4;6)(4qter-,6pter+)dn }\end{array}$ & $\begin{array}{l}\text { 46, XX.arr cgh } \\
\text { 4q22.1q23 } \\
(93,972,073- \\
101,811,206) \times 1 \mathrm{dn} .\end{array}$ & $\begin{array}{l}\text { Deletion is located at } \\
4 \mathrm{q} 28.3-31.23\end{array}$ \\
\hline $\begin{array}{l}\text { Abnormal parental } \\
\text { chromosomes }\end{array}$ & Paternal & - & No & No & - \\
\hline Sex & Female & Female & Male & Female & Female \\
\hline Growth retardation & Yes & Yes & Yes & Yes & Yes \\
\hline Feeding proplem & Yes & - & - & Yes & Yes \\
\hline Developmental delay & Yes & - & - & - & - \\
\hline Nervous system & Hypotonia & - & - & Hypotonia & Hypotonia \\
\hline Endocrine system & No & - & - & - & Hyperparathyroidism \\
\hline Ocular defect & Possible visual defect & - & - & $\begin{array}{l}\text { Anisocoria } \\
\text { Microcornea }\end{array}$ & - \\
\hline Hearing defect & Possible hearing defect & - & - & No & - \\
\hline Craniofacial dysmorphism & $\begin{array}{l}\text { Frontal bossing } \\
\text { Hypertelorism } \\
\text { Anteverted nares } \\
\text { Low set ears } \\
\text { Micrognathia }\end{array}$ & $\begin{array}{l}\text { Low set ears } \\
\text { High arched palate } \\
\text { Cleft palate } \\
\text { Micrognathia }\end{array}$ & $\begin{array}{l}\text { Microcephaly } \\
\text { Hypertelorism } \\
\text { Broad nasal bridge } \\
\text { Cleft palate } \\
\text { Micrognathia }\end{array}$ & $\begin{array}{l}\text { Frontal bossing } \\
\text { Telecanthus } \\
\text { Broad nasal bridge } \\
\text { Low set ears } \\
\text { Micrognathia }\end{array}$ & $\begin{array}{l}\text { Low set ear } \\
\text { Short philtrum } \\
\text { High arched palate } \\
\text { Facial Hemihypertrophy }\end{array}$ \\
\hline Cardiovascular anomaly & Yes & Yes & Yes & No & Yes \\
\hline Genitourinary anomaly & No & - & $\begin{array}{l}\text { Cryptorchidism } \\
\text { Hypospadias }\end{array}$ & - & - \\
\hline Digital anomaly & - & No & $\begin{array}{l}\text { Malposition of digits } \\
\text { Short 5th finger }\end{array}$ & $\begin{array}{l}\text { Clinodactly } \\
\text { Overlapping } \\
\text { 2nd/3rd toes }\end{array}$ & - \\
\hline
\end{tabular}

-, absence. 
cal milestones. She also needs to receive regular therapy at the rehabilitation department for global delayed development. The spectrum of this phenotype ranges from mild to severe. Reciprocal translocations, the most common structural rearrangements of chromosomes in humans, occur at a frequency of approximately 1:500 in the general population [11]. Reciprocal translocation does not change the amount of chromosomal material. As with the father's balanced translocation, 25\% of cases are normal, 50\% manifest unbalanced translocation, and 25\% manifest balanced translocation. Reciprocal translocations have various modes of segregation, depending on the chromosomes involved, the locations of the breakpoints, and hence translocated segment sizes, and the gender of the carrier $[12,13]$. Estimating risks is difficult, because the risk for an individual carrier depends on each translocation breakpoint. Depending on the sex and the involvement of the chromosome area for the break point, the recurrence risk may be higher. Because there is very little or no loss of genetic material, balanced translocation carriers are phenotypically healthy, but they are at increased risk of fertility issues, resulting in recurrent miscarriages or children with severe congenital disorders $[14,15]$. The frequency of adverse reproductive outcomes can reach up to $5 \%$ in translocation carriers, compared to less than $1 \%$ in the general population [16]. Genetic consultation can facilitate the identification of balanced translocation carriers in individuals with fertility problems, providing explanations for poor reproductive outcome, and allowing adjustments in treatment strategies. If a mother or father is found to be a balanced translocation carrier, it is helpful for them to know about the risk of congenital anomalies in their offspring, in order to prepare for the special needs and health problems, which may be caused by a chromosomal disorder. It is also important to note, however, that their offspring can be born with an ordinary chromosome pattern. These outcomes will be more or less likely, depending on particular translocations, how large the pieces are, and on the break points. Genetic diagnoses help to establish a clear family genetic background, permitting the development of treatment strategies. Genetic consultation can facilitate the identification of balanced translocation carriers in in vitro fertilization-assisted families, providing an explanation for poor reproductive outcomes and allowing for adjustments to be made in treatment strategies. Prenatal counseling can help understand the possible risks associated with a specific pregnancy.

\section{Acknowledgements}

We are grateful to the family for their consent in undertaking this study.

\section{References}

1. Strehle EM, Ahmed OA, Hameed M, Russell A. The 4q-syndrome. Genet Couns 2001;12:327-39.

2. Strehle EM, Bantock HM. The phenotype of patients with 4q-syndrome. Genet Couns 2003;14:195-205.

3. Descartes M, Keppler-Noreuil K, Knops J, Longshore JW, Finley WH, Carroll AJ. Terminal deletion of the long arm of chromosome 4 in a mother and two sons. Clin Genet 1996;50:538-40.

4. Strehle EM, Gruszfeld D, Schenk D, Mehta SG, Simonic I, Huang T. The spectrum of $4 q-$ syndrome illustrated by a case series. Gene 2012;506:387-91.

5. Strehle EM, Yu L, Rosenfeld JA, Donkervoort S, Zhou Y, Chen TJ, et al. Genotype-phenotype analysis of $4 q$ deletion syndrome: proposal of a critical region. Am J Med Genet A 2012;158A:2139-51.

6. Cingoz S, Bisgaard AM, Bache I, Bryndorf T, Kirchoff M, Petersen W, et al. 4q35 deletion and 10p15 duplication associated with immunodeficiency. Am J Med Genet A 2006;140:2231-5.

7. Andreakos $E_{1}$ Foxwell $B$, Feldmann M. Is targeting Toll-like receptors and their signaling pathway a useful therapeutic approach to modulating cytokine-driven inflammation? Immunol Rev 2004;202:25065.

8. Xu W, Ahmad A, Dagenais S, lyer RK, Innis JW. Chromosome 4q deletion syndrome: narrowing the cardiovascular critical region to 4q32.2-q34.3. Am J Med Genet A 2012;158A:635-40.

9. Taub PJ, Wolfeld M, Cohen-Pfeffer J, Mehta L. Mandibular distraction in the setting of chromosome $4 q$ deletion. J Plast Reconstr Aesthet Surg 2012;65:e95-8.

10. Duga B, Czako M, Komlosi K, Hadzsiev K, Torok K, Sumegi K, et al. Deletion of $4 q 28.3-31.23$ in the background of multiple malformations with pulmonary hypertension. Mol Cytogenet 2014;7:36.

11. Jacobs PA. Epidemiology of chromosome abnormalities in man. Am J Epidemiol 1977;105:180-91.

12. Ye $Y$, Qian $Y, X u C$, Jin F. Meiotic segregation analysis of embryos from reciprocal translocation carriers in PGD cycles. Reprod Biomed Online 2012;24:83-90.

13. Dul E, van Echten-Arends J, Groen H, Kastrop P, Wissen LA, Engelen $J$, et al. Can characteristics of reciprocal translocations predict the chance of transferable embryos in PGD cycles? J Clin Med 2014;3:348-58.

14. Idowu D, Merrion K, Wemmer N, Mash JG, Pettersen B, Kijacic D, et al. 
Pregnancy outcomes following 24-chromosome preimplantation genetic diagnosis in couples with balanced reciprocal or Robertsonian translocations. Fertil Steril 2015;103:1037-42.

15. Sugiura-Ogasawara M, Ozaki Y, Sato T, Suzumori N, Suzumori K. Poor prognosis of recurrent aborters with either maternal or paternal reciprocal translocations. Fertil Steril 2004;81:367-73.

16. De Braekeleer M, Dao TN. Cytogenetic studies in couples experiencing repeated pregnancy losses. Hum Reprod 1990;5:519-28. 